\title{
Immunomodulatory activity of IR700-labelled affibody targeting HER2
}

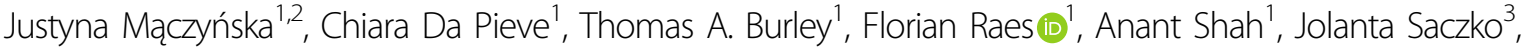 \\ Kevin J. Harrington (iD) and Gabriela Kramer-Marek ${ }^{1}$
}

\begin{abstract}
There is an urgent need to develop therapeutic approaches that can increase the response rate to immuno-oncology agents. Photoimmunotherapy has recently been shown to generate anti-tumour immunological responses by releasing tumour-associated antigens from ablated tumour cell residues, thereby enhancing antigenicity and adjuvanticity. Here, we investigate the feasibility of a novel HER2-targeted affibody-based conjugate ( $Z_{\text {HER2:2395-IR700) }}$ selectively to induce cancer cell death in vitro and in vivo. The studies in vitro confirmed the specificity of $Z_{\text {HER2:2395- }}$ IR700 binding to HER2-positive cells and its ability to produce reactive oxygen species upon light irradiation. A conjugate concentration- and light irradiation-dependent decrease in cell viability was also demonstrated.

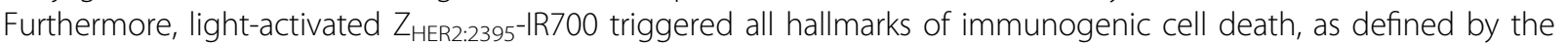
translocation of calreticulin to the cell surface, and the secretion of ATP, HSP70/90 and HMGB1 from dying cancer cells into the medium. Irradiating a co-culture of immature dendritic cells (DCs) and cancer cells exposed to light-activated

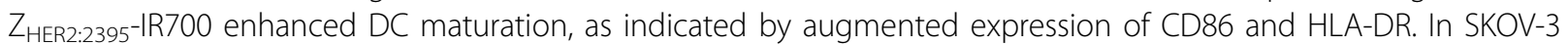

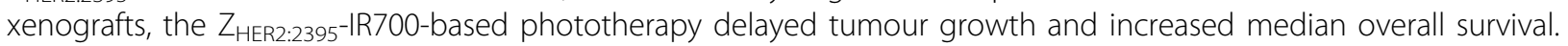
Collectively, our results strongly suggest that $Z_{\text {HER2:2395-IR700 is a promising new therapeutic conjugate that has great }}$ potential to be applicable for photoimmunotherapy-based regimens.
\end{abstract}

\section{Introduction}

Immunotherapy with immune checkpoint inhibitors (ICPIs) has recently shown encouraging clinical benefits in cancer patients; however, the response rates are still limited, ranging between $10 \%$ and $50 \%{ }^{1,2}$. The reasons for this are multifactorial and include a relatively immunedepleted ("cold") microenvironment, an absence of tumour-infiltrating lymphocytes (TILs), a state of phenotypic exhaustion in those cytotoxic $\mathrm{T}$ lymphocytes (CTLs) that are present and the actions of potent negative regulators, such as regulatory $\mathrm{T}$ cells ${ }^{3,4}$. Nevertheless, a growing body of research has indicated that patients whose tumours are already infiltrated with $\mathrm{T}$ cells benefit

\footnotetext{
Correspondence: Gabriela Kramer-Marek (gkramermarek@icr.ac.uk)

'Division of Radiotherapy and Imaging, The Institute of Cancer Research,

London, UK

2Department of Medical Biochemistry, Wroclaw Medical University, Wroclaw, Poland

Full list of author information is available at the end of the article

Edited by P. Agostinis
}

from treatment with ICPIs ${ }^{5}$. Therefore, development of therapeutic strategies that trigger anti-tumour immunological responses by generating tumour-associated antigens from ablated tumour cell residues could significantly improve the efficacy of systemic immunotherapy.

It is widely recognised that conventional photodynamic therapy (PDT) and photoimmunotherapy (PIT) can induce immunogenic cell death (ICD), as defined by hallmarks such as translocation of calreticulin (CRT) to the plasma membrane, ATP secretion and release of highmobility group box-1 (HMGB1) nuclear protein and heat shock proteins HSP70/906,7. Accordingly, this can elicit uptake of antigenic components by dendritic cells (DCs), resulting in the expansion of antigen-specific CTLs ${ }^{8-10}$.

Both PDT and PIT are based on a photochemical reaction between light of a defined wavelength, a photosensitiser (PS) and molecular oxygen. The combination of these components causes cell death by generating cytotoxic molecules. However, in PIT the PS is conjugated to a

\section{(c) The Author(s) 2020}

(c) (i) Open Access This article is licensed under a Creative Commons Attribution 4.0 International License, which permits use, sharing, adaptation, distribution and reproduction cc) in any medium or format, as long as you give appropriate credit to the original author(s) and the source, provide a link to the Creative Commons license, and indicate if changes were made. The images or other third party material in this article are included in the article's Creative Commons license, unless indicated otherwise in a credit line to the material. If material is not included in the article's Creative Commons license and your intended use is not permitted by statutory regulation or exceeds the permitted use, you will need to obtain permission directly from the copyright holder. To view a copy of this license, visit http://creativecommons.org/licenses/by/4.0/. 
highly specific monoclonal antibody (mAb) that can engage the selected target of interest, enabling a greater degree of tumour specificity than $\mathrm{PDT}^{11,12}$. Recent developments in antibody engineering technology have also led to a new wave of PIT-suitable agents that are built on a range of antibody fragments and affibodies ${ }^{13-16}$. Following excitation with near-infrared (NIR) light, these conjugates can cause rapid and irreversible selective disruption of membrane integrity and preferential killing of malignant cells, while sparing normal adjacent tissue ${ }^{17,18}$. This, in turn, can activate anti-tumour immunological responses, stimulated by the release of tumour-associated antigens $^{7,14,19,20}$. Various PSs have been tested for PIT purposes and the silicon phthalocyanine dye, IRDye700DX (henceforth referred to as IR700) has, so far, shown the most favourable properties. This dye has excellent water solubility and a greater than five-fold higher extinction coefficient $\left(2.1 \times 10^{5} \mathrm{M}^{-1} \mathrm{~cm}^{-1}\right.$ at the maximum absorption wavelength of $689 \mathrm{~nm}$ ) than other conventional PSs in the NIR part of the spectrum, which allows increased tissue penetration of the activating light ${ }^{12}$. Excitingly, an EGFR-targeting IR700-cetuximab conjugate (RM1929) is currently being investigated in a global Phase 3 clinical trial in head and neck cancer (https://clinicaltrials.gov/ct2/show/NCT03769506). Here, we evaluate the immunomodulatory activity of a novel affibody-based conjugate specifically targeting the human epidermal growth factor receptor 2 (HER2). For that purpose, we attached IR700 to a low molecular weight $(\sim 7 \mathrm{kDa})$, three-helix $\mathrm{Z}_{\mathrm{HER} 2: 2395}$ affibody molecule that recognises HER2 with high selectivity and affinity. We chose HER2 as a target of interest because it is a major driver in the progression of epithelial neoplasms, including breast and ovarian cancers ${ }^{21}$. Furthermore, HER2 is involved in regulating cell growth, survival and differentiation through networked downstream signal transduction pathways, including PI3K/AKT/mTOR and Ras/ Raf/MAPK ${ }^{22}$. HER2-positive tumours are also associated with resistance to certain types of chemotherapy, hormone therapy and ionizing radiation ${ }^{23}$. Consequently, numerous drugs specifically targeting the receptor, such as mAbs (e.g., trastuzumab, pertuzumab), antibody-drug conjugates (e.g., trastuzumab-emtansine T-DM1), and pan-HER small molecule inhibitors (e.g., dacomitinib, afatinib), have been developed. Although, the majority of patients initially respond to these HER2-targeted agents, they frequently acquire resistance and, subsequently present disease progression within 8-18 months ${ }^{24,25}$. Therefore, there is an unmet clinical need for more effective therapeutic approaches that maximize target-cell killing in HER2-positive cancers to achieve substantial remissions. In this study, we demonstrate that $\mathrm{Z}_{\text {HER2:2395- }}$ IR700-based phototherapy leads to HER2-specific cell death, release of danger-associated molecular patterns
(DAMPs) which subsequently induce DC maturation in vitro. Moreover, the treatment in vivo results in significant tumour growth inhibition.

\section{Results \\ In vitro cellular uptake and internalization of $Z_{\text {HER2:2395- }}$ IR700}

Maleimide-functionalized IR700 was attached to a unique C-terminal cysteine on the HER2-specific affibody

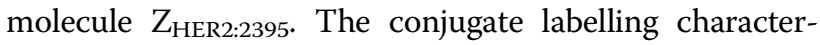
istics are shown in Fig. S1A, B. The binding specificity of $Z_{\text {HER2:2395-IR700 was evaluated using a panel of breast and }}$ ovarian cancer cell lines expressing different HER2 levels as indicated by the Western blot (Fig. 1A). The specific and receptor-dependent targeting of the conjugate correlated with the receptor expression level as measured by flow cytometry (Fig. 1B and Fig. S2A). The fluorescence signal was significantly reduced in the presence of 50-fold excess of non-labelled $Z_{\text {HER2:2395, confirming the con- }}$ jugate binding specificity. The receptor binding affinity of $\mathrm{Z}_{\text {HER2:2395-IR700 was assessed by flow cytometry using }}$ SKOV-3 cells (HER2-positive). The conjugate showed a high affinity for HER2 with a $K_{\mathrm{D}}=7.5 \pm 0.9 \mathrm{nM}$ (Fig. S1C). Consistent with our prior results, cells incubated with IR700 alone demonstrated a very low uptake of the dye (Fig. 1B $)^{14}$. Highly specific cell binding and uptake of $\mathrm{Z}_{\text {HER2:2395-IR700 was also captured by confocal micro- }}$ scopy. Intense membrane fluorescence was visualised in SKOV-3 cells (HER2-positive $1 \mathrm{~h}$ post-incubation with the conjugate, whereas no membrane-associated fluorescence was captured in MDA-MB-468 cells (HER2-negative) (Fig. 1C). Furthermore, incubating SKOV-3 cells with the conjugate for 1,4 , or $6 \mathrm{~h}\left(37^{\circ} \mathrm{C}\right)$ allowed acquisition of a distinct, cytoplasmic fluorescence signal that prominently increased over time (Fig. S2B). In addition, to investigate the penetration of the affibody conjugate, SKOV-3 spheroids were incubated with the same concentration of either $\mathrm{Z}_{\mathrm{HER} 2: 2395}$-IR700 or $\mathrm{mAb} \mathrm{H}_{\mathrm{HER} 2}$-FITC for $6 \mathrm{~h}\left(37^{\circ} \mathrm{C}\right)$. The spheroids treated with the affibody-based conjugate exhibited significantly higher intracellular fluorescence intensity and more homogeneous fluorescence distribution compared to spheroids incubated with $\mathrm{mAb}_{\mathrm{HER} 2^{-}}$ FITC, showing at the same time also greater penetration (Fig. 1D). The H\&E staining of spheroid sections $(\sim 250 \mu \mathrm{m}$ in diameter) confirmed a lack of necrotic cores and the presence of actively proliferating (Ki67-positive) HER2-positive cells within the 3D structures (Fig. S2C).

\section{Receptor-mediated cell death induced by $Z_{\text {HER2:2395-IR700 }}$ mediated-treatment}

Next, we assessed the response to $Z_{\text {HER2:2395-IR700- }}$ mediated phototherapy in vitro using SKOV-3 2D monolayer cultures and 3D cell spheres incubated either with IR700 $(1 \mu \mathrm{M})$ or $\mathrm{Z}_{\mathrm{HER} 2: 2395}$-IR700 $(0.01-1 \mu \mathrm{M})$ for $6 \mathrm{~h}$ 

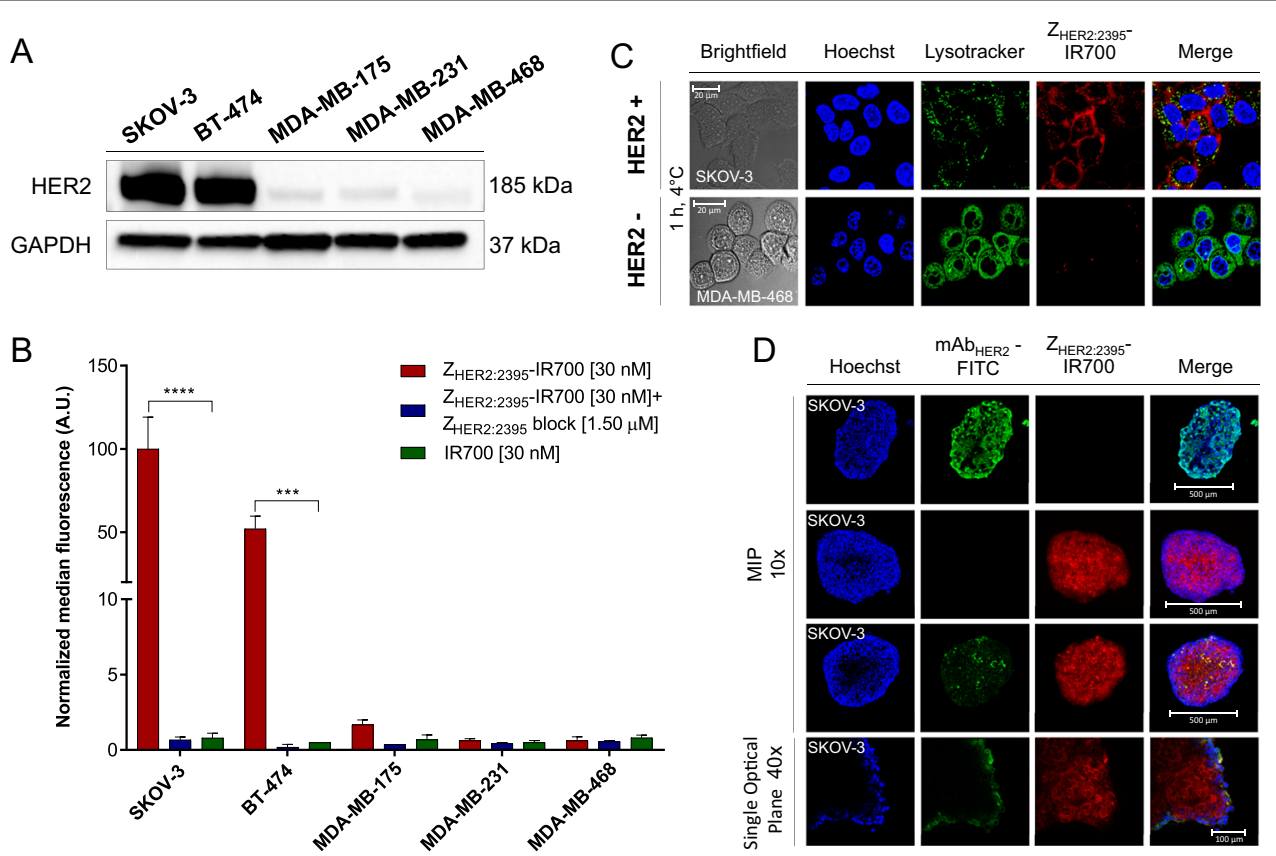

Fig. 1 Expression of HER2 in tumour cell lines and specificity of the ZHER2:2395-IR700 binding. A HER2 expression levels detected by Western blot in a panel of cancer cell lines. B $Z_{\text {HER2:2395 }}-$ IR700 $(30 \mathrm{nM})$ binding $\left(1 \mathrm{~h}, 4^{\circ} \mathrm{C}\right)$ assessed by flow cytometry with or without blocking with 50 -fold

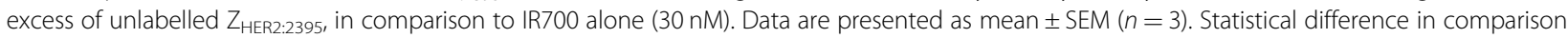

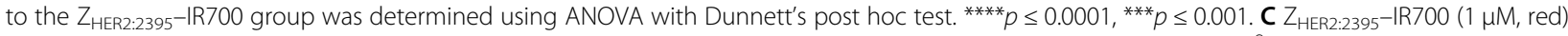
cell binding $\left(1 \mathrm{~h}, 4^{\circ} \mathrm{C}\right)$ assessed by confocal microscopy using SKOV-3 HER2+ve $_{\text {end MDA-MB-468 }}$ HeR2-ve cells. Hoechst 33342 (blue) and LysoTracker ${ }^{T M}$ Green DND-26 (green) were used for counterstaining. D Maximum intensity projections (MIPs) of SKOV-3 spheroids incubated with

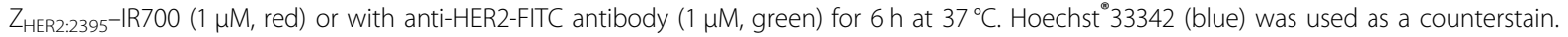

(due to increased conjugate accumulation; Fig. S2B). Based on our previous work with EGFR-targeting conjugate, samples were irradiated with a light-dose of $16 \mathrm{~J} /$ $\mathrm{cm}^{2}$ to activate the photosensitiser ${ }^{14}$. A significant decrease ( 85-97\%) in cell viability within the 3D SKOV3 spheres post-treatment was detected at $96 \mathrm{~h}$ and the percentage of dying cells was influenced by the con-

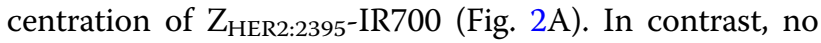
toxicity was observed when spheroids were exposed to

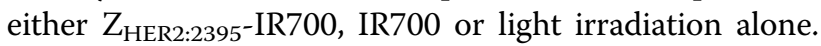
Furthermore, the majority of cells were viable when the spheroids were subjected to IR700-based phototherapy or pre-incubated with 50 -fold excess of non-labelled affibody molecules prior to $Z_{\text {HER2:2395-IR700 treatment, which }}$ confirmed receptor-mediated cell phototoxicity. In 2D HER2-positive monolayer cultures (BT474, SKOV-3), we also observed a significant decrease in the luminescence signal in a conjugate concentration-dependent manner $24 \mathrm{~h}$ post-treatment (Fig. S3A, B). Conversely, the same treatment regimen had no effect on HER2-negative MDA-MB-468 cells (Fig. S3C). Irradiation of cells incubated with IR700 dye alone resulted in considerable $(\sim 11-44 \%)$ loss in cell viability regardless of the HER2 expression level (Fig. S3A-C). In addition, there was no decrease in cell viability when the $Z_{\text {HER2:2395-IR700, }}$
IR700, or NIR light were used alone in either of the cell lines. Moreover, we observed a substantial generation of reactive oxygen species (ROS) post- $\mathrm{Z}_{\mathrm{HER} 2: 2395}$-IR700 irradiation (Fig. S3D). Importantly, cell viability was partially rescued by pre-treatment with a radical scavenger (N-acetylcysteine, NAC) or apoptosis inhibitor (pan-caspase Z-VAD-FMK), confirming a role for oxidative stressinduced cell death in response to $Z_{\text {HER2:2395-IR700- pho- }}$ totherapy (Fig. S3E). Finally, in order to depict cell death morphological changes induced by $\mathrm{Z}_{\mathrm{HER} 2: 2395}$-IR700phototherapy, SKOV-3 spheroids were imaged 1, 24, $96 \mathrm{~h}$ post-irradiation. As demonstrated on the bright-field images (Fig. 2B), the treatment did not result in spheroid growth inhibition. However, we observed cellular swelling, increased membrane disruption and cell displacement from the dense sphere core, which formed a loose spheroid periphery as early as $1 \mathrm{~h}$ post-irradiation. In order to identify both viable and necrotic cells within the 3D spheres, live/dead fluorescence staining was additionally performed $96 \mathrm{~h}$ post-light exposure. The resulting maximum intensity projections (MIP) of the entire image z-stacks indicated an affibody concentrationdependent decrease in the viability of cells $96 \mathrm{~h}$ posttreatment. Incorporation of EthD-1 (dead cells) confirmed significant cell damage leading to acute necrosis (Fig. 2C). 


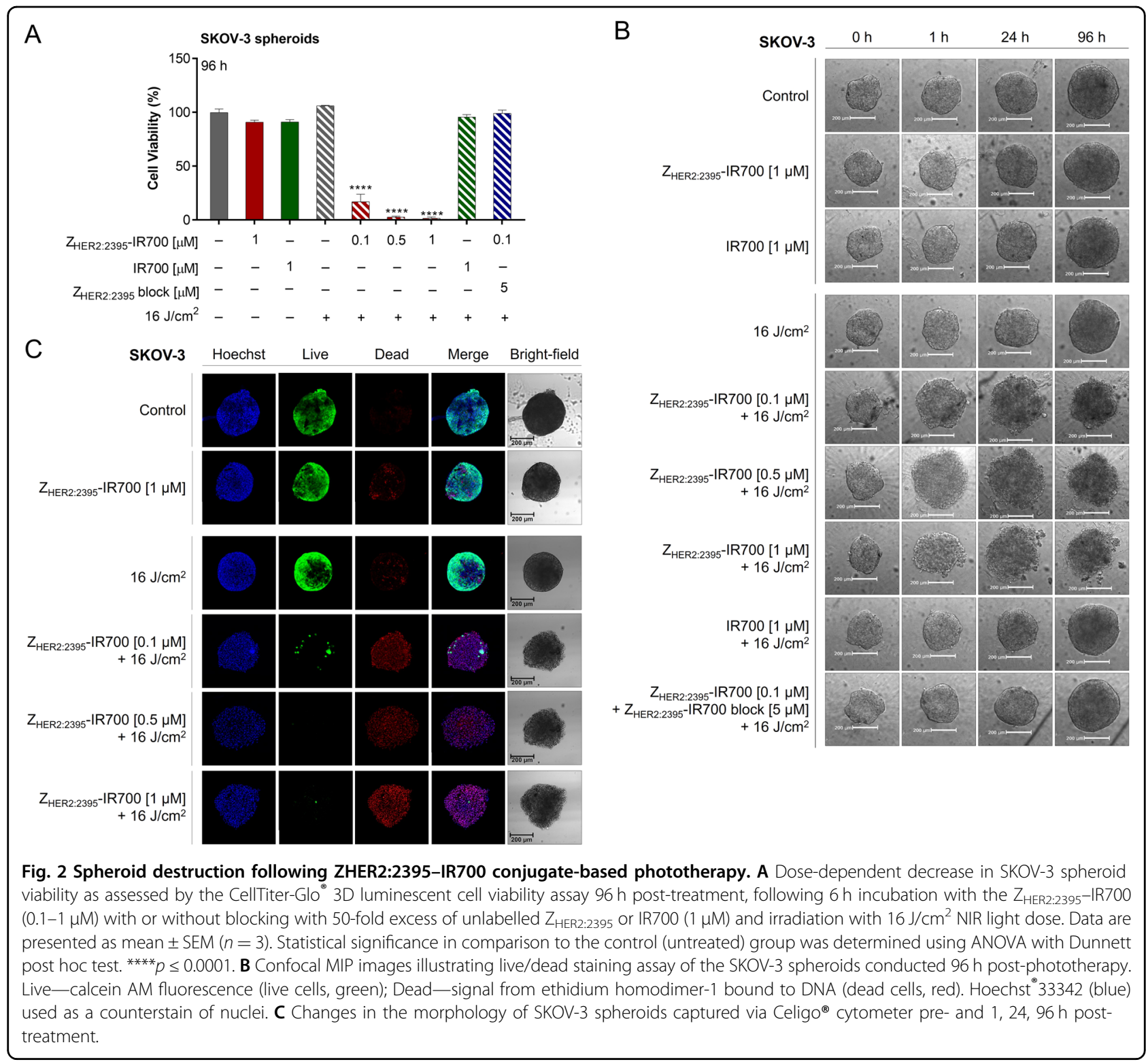

In contrast, there was only negligible cell death in spheres treated with the conjugate or irradiated with light alone.

\section{$\mathrm{Z}_{\text {HER2:2395-IR700-based treatment triggers the release of }}$ DAMPs in vitro}

As PIT induces ICD, a mode of death where dying cancer cells release DAMPs, we next analysed major endogenous danger molecules: CRT, ATP, HSP70/90, and HMGB1.

The treatment with either the conjugate, IR700 or light alone had little phototoxic effect on cell viability (Fig. 3A, $B$ and Fig. S4A). Conversely, $Z_{\text {HER2:2395-IR700-based }}$ therapy induced cell death in both a light dose- and $\mathrm{Z}_{\text {HER2:2395-IR700 concentration-dependent manner. The }}$ cell population shifted from viable to necrotic and the number of necrotic cells (Annexin $\mathrm{V}+/ \mathrm{PI}+$ ) peaked at $24 \mathrm{~h}$ post-irradiation (Fig. 3B and Fig. S4A), where $\sim 47 \%$ of cells were dead when $1 \mu \mathrm{M}$ of the conjugate and a light dose $16 \mathrm{~J} / \mathrm{cm}^{2}$ were used, compared to $\sim 2 \%$ of the untreated control. However, only $\sim 30 \%$ of cells were necrotic when treated with $0.1 \mu \mathrm{M}$ of the conjugate and a light dose $8 \mathrm{~J} / \mathrm{cm}^{2}$. After $24 \mathrm{~h}$, there was significant increase in the subpopulation of apoptotic cells $(\sim 28 \%)$, regardless of $Z_{\text {HER2:2395-IR700-based therapy regimen. }}$ Therefore, $0.1 \mu \mathrm{M}$ of the conjugate and a light dose of $8 \mathrm{~J} /$ $\mathrm{cm}^{2}$ were selected as conditions for the subsequent experiments to investigate the generation of DAMPs in response to $\mathrm{Z}_{\text {HER2:2395-IR700 phototherapy. Confocal }}$ microscopy images acquired $1 \mathrm{~h}$ post-treatment demonstrated redistribution of CRT within cellular membrane 


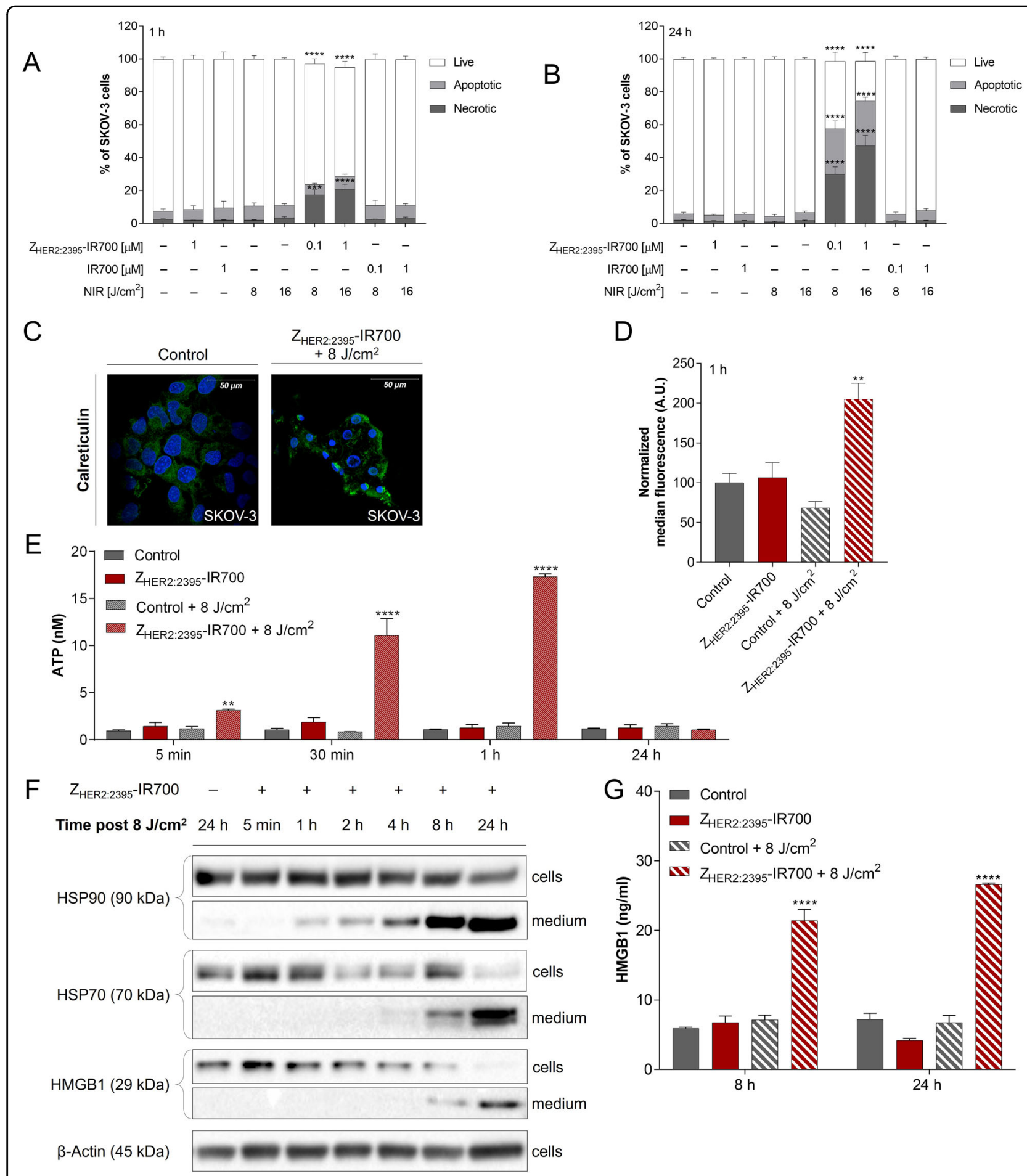

Fig. 3 (See legend on next page.)

(Fig. 3C). Data were in agreement with the enhanced surface expression of CRT as measured by flow cytometry on live cells (Fig. 3D and Fig. S4B). Furthermore, there was a significant secretion of ATP as early as 5 min postirradiation (Fig. 3E). A prominent release of HSP70/90 and HMGB1 from the cells to the medium following 
(see figure on previous page)

Fig. 3 Immunogenic cell death (ICD) triggered by HER2 targeted phototherapy. A, B Changes in percentage of live, apoptotic and necrotic SKOV-3 cell populations measured $1 \mathrm{~h}$ (A) and $24 \mathrm{~h}$ (B) post-therapy, following $1 \mathrm{~h}$ incubation with the $\mathrm{Z}_{\text {HER2:2395 }}$ IR700 (0.1 or $\left.1 \mu \mathrm{M}\right)$ or IR700 (0.1 or $1 \mu \mathrm{M}$ ) and exposure to 8 or $16 \mathrm{~J} / \mathrm{cm}^{2}$ light dose. C Translocation of calreticulin (CRT) to the cellular membrane as illustrated by confocal microscopy, following immunofluorescence staining with anti-calreticulin-AlexaFluor 405 antibody (overnight incubation in $4^{\circ} \mathrm{C}$ ) of methanol-fixed SKOV-3 cells untreated or $1 \mathrm{~h}$ post-phototherapy $\left(0.1 \mu \mathrm{M} \mathrm{Z}_{\text {HER2:2395 }}-\mathrm{IR700}+8 \mathrm{~J} / \mathrm{cm}^{2}\right)$. D Quantitative analysis of calreticulin translocation into the SKOV-3 cell membrane $1 \mathrm{~h}$ post-irradiation assessed by flow cytometry, following indirect immunofluorescence staining of live cells with primary rabbit anticalreticulin antibody ( $30 \mathrm{~min}$ incubation in $4^{\circ} \mathrm{C}$ ) and secondary anti-rabbit-AlexaFluor ${ }^{\otimes} 488$ antibody $\left(30\right.$ min incubation in $4^{\circ} \mathrm{C}$ ). E The amount of ATP released into the medium from SKOV-3 cells over time $(5,30 \mathrm{~min}, 1$ or $24 \mathrm{~h})$ post-treatment ( $1 \mathrm{~h}$ incubation with or without $\mathrm{Z}_{\mathrm{HER} 2: 2395}$-IR700 (0.1 $\left.\mu \mathrm{M}\right)$ with or without irradiation $\left(8 \mathrm{~J} / \mathrm{cm}^{2}\right)$. F The expression level of HSP70, HSP90 and HMGB1 proteins in SKOV-3 cells and cell supernatants (medium) over time (30 min, 1, 2, 4, 8 or $24 \mathrm{~h}$ ) post-treatment $\left(0.1 \mu \mathrm{M} \mathrm{Z}_{\text {HER2:2395 }}-\mathrm{IR} 700+8 \mathrm{~J} / \mathrm{cm}^{2}\right)$ in comparison to irradiated control cells $\left(8 \mathrm{~J} / \mathrm{cm}^{2}\right)$ assessed by Western blot. $\beta$-actin was used as loading control. G HMGB1 protein level released into the medium $8 \mathrm{~h}$ and $24 \mathrm{~h}$ post-treatment $(0.1 \mu \mathrm{M}$

$\left.Z_{\text {HER2:2395 }}-\mathrm{IR700}+8 \mathrm{~J} / \mathrm{cm}^{2}\right)$ as measured by ELISA assay. All data are presented as mean $\pm \mathrm{SEM}(n=3)$. Statistical significance in comparison to the control (untreated) group was determined using ANOVA with Dunnett's post hoc test. ${ }^{* * *} p \leq 0.0001,{ }^{* * *} p \leq 0.001,{ }^{* *} p \leq 0.01$.

treatment with $\mathrm{Z}_{\mathrm{HER} 2: 2395}$-IR700 was also detected by Western blot (Fig. 3F). Densitometric analysis confirmed that HSP70/90 and HMGB1 expression in medium markedly increases between 1 and $24 \mathrm{~h}$ (Fig. S4C). Consistent with these results, the expression level of HMGB1 in the medium, measured by an ELISA assay, reached the highest value $(26.6 \pm 0.4 \mathrm{ng} / \mathrm{mL}$ vs $7.2 \pm 1.8 \mathrm{ng} / \mathrm{mL}$ for the control) at $24 \mathrm{~h}$ post-treatment initiation (Fig. 3G). No significant upregulation of DAMPs was detectable when light or conjugate-only treated-cells were studied. In addition, to verify the role of DAMPs in the maturation of DCs stimulated by $Z_{\text {HER2:2395-IR700 phototherapy, we co- }}$ cultured DCs with irradiated SKOV-3 cells for $48 \mathrm{~h}$. Flow cytometry analysis showed that the expression of CD86 and HLA-DR molecules on the surface of DCs stimulated by LPS (positive control) or by $\mathrm{Z}_{\mathrm{HER} 2: 2395}$-IR700 $+16 \mathrm{~J} /$ $\mathrm{cm}^{2}$ substantially and simultaneously increased compared to the negative controls (Fig. 4A and Fig. S5A-C). Furthermore, inflammatory cytokines including IL-6, TNF- $\alpha$ and IL-10 were elevated in supernatants from SKOV-3DC co-cultures following treatment, as assessed by ELISA (Fig. 4B, D).

\section{Irradiation of tumours post- $\mathrm{Z}_{\text {HER2:2395-IR700 treatment }}$ leads to strong inhibition of tumour growth}

To demonstrate the tumour-targeting efficacy of $\mathrm{Z}_{\text {HER2:2395-IR700 in vivo, mice bearing subcutaneous }}$ BT474 tumours were injected intravenously with three different concentrations of the conjugate $(0.5,3$ or $18 \mu \mathrm{g}$ per mouse). The tumour fluorescence was monitored in vivo using an IVIS/Spectrum optical imaging system at different time points (Fig. S6A, B). 2D-fluorescence images acquired as early as $1 \mathrm{~h}$ post- $\mathrm{Z}_{\mathrm{HER2} 22395}$-IR700 injection demonstrated clear delineation of tumours when 3 or $18 \mu \mathrm{g}$ of the conjugate was administered (Fig. 5A and Fig. S6C). As shown in Fig. 5B, the injected conjugate quantity of $18 \mu \mathrm{g} /$ mouse yielded a tumour-to-background ratio of 3.2. However, the semi-quantitative fluorescence signal intensities estimated from image ROIs slightly decreased over time to $(1.00 \pm 0.15) \times 10^{8}\left(\mathrm{p} / \mathrm{s} / \mathrm{cm}^{2} / \mathrm{sr}\right) \times \mathrm{cm}^{2} / \mu \mathrm{W}$ for a $3 \mu \mathrm{g} /$ mouse dose and $(3.35 \pm 0.41) \times 10^{8}\left(\mathrm{p} / \mathrm{s} / \mathrm{cm}^{2} / \mathrm{sr}\right) \times$ $\mathrm{cm}^{2} / \mu \mathrm{W}$ for a $18 \mu \mathrm{g} /$ mouse dose at $24 \mathrm{~h}$ (Fig. S6A). Only negligible tumour uptake $\left((0.53 \pm 0.11) \times 10^{8}\left(\mathrm{p} / \mathrm{s} / \mathrm{cm}^{2} /\right.\right.$ $\mathrm{sr}) \times \mathrm{cm}^{2} / \mu \mathrm{W}$; tumour-to-background ratio $1.24 \pm 0.07$ ) was found when the lowest dose $0.5 \mu \mathrm{g} /$ mouse was injected (Fig. 5A, B and Fig. S6A-C). Of note, no fluorescence signal was observed in mice injected with saline (Fig. S6D). Importantly, the imaging data were corroborated by ex vivo biodistribution studies that showed a tumour uptake of $(2.25 \pm 0.04) \times 10^{8}\left(\mathrm{p} / \mathrm{s} / \mathrm{cm}^{2} / \mathrm{sr}\right) \times \mathrm{cm}^{2} / \mu \mathrm{W}$ (tumour-to-muscle ratio of $10.17 \pm 2.76) 1 \mathrm{~h}$ postinjection and $(1.78 \pm 0.51) \times 10^{8}\left(\mathrm{p} / \mathrm{s} / \mathrm{cm}^{2} / \mathrm{sr}\right) \times \mathrm{cm}^{2} / \mu \mathrm{W}$ at $24 \mathrm{~h}$ (tumour-to-muscle ratio $12.55 \pm 3.35$ ) (Fig. $5 \mathrm{~B}$ and Fig. S6C). Furthermore, as shown in Fig. 5C, intense fluorescence signal was detected in the kidney at 1 and $24 \mathrm{~h}$ post-injection, which is consistent with the known excretion profile of affibody molecules ${ }^{26}$. In addition, uptake in the liver and lungs gave an initial strong fluorescence signal, which markedly decreased at $24 \mathrm{~h}$ (Fig. 5C, D and Fig. S6E). This may be attributed to the lipophilicity of the dye. The heart and small intestines showed fluorescence signal just above the muscle level (background). In parallel, we also injected a group of SKOV-3 xenografts $(n=6)$ with $18 \mu \mathrm{g} /$ mouse of the conjugate. Since, the measured radiant efficiency attrib-

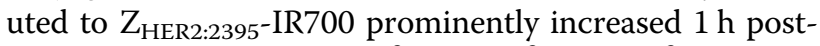
injection $\left((6.20 \pm 0.33) \times 10^{8}\left(\mathrm{p} / \mathrm{s} / \mathrm{cm}^{2} / \mathrm{sr}\right) \times \mathrm{cm}^{2} / \mu \mathrm{W}\right)$, the SKOV-3 tumour model and $1 \mathrm{~h}$ time point were selected for subsequent $\mathrm{Z}_{\mathrm{HER} 2: 2395}$-IR700-mediated phototherapy studies (Fig. 5A, B and Fig. S6C). Importantly, the tumour uptake in both xenograft models correlated with the HER2 expression level as assessed ex vivo by IHC staining (Fig. 5E). After confirming conjugate uptake in vivo, we hypothesised that phototherapy with $\mathrm{Z}_{\text {HER2:2395-IR700 }}$ would lead to significant delay in tumour growth. Following SKOV-3 tumour establishment (volume of $\sim 50 \mathrm{~mm}^{3}$ ), mice were randomly divided into four groups (day 0) (i) control (no treatment), (ii) $100 \mathrm{~J} / \mathrm{cm}^{2}$, (iii)

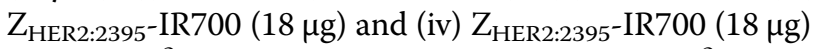
$+100 \mathrm{~J} / \mathrm{cm}^{2}$. Irradiating tumours with $100 \mathrm{~J} / \mathrm{cm}^{2}$ led to 


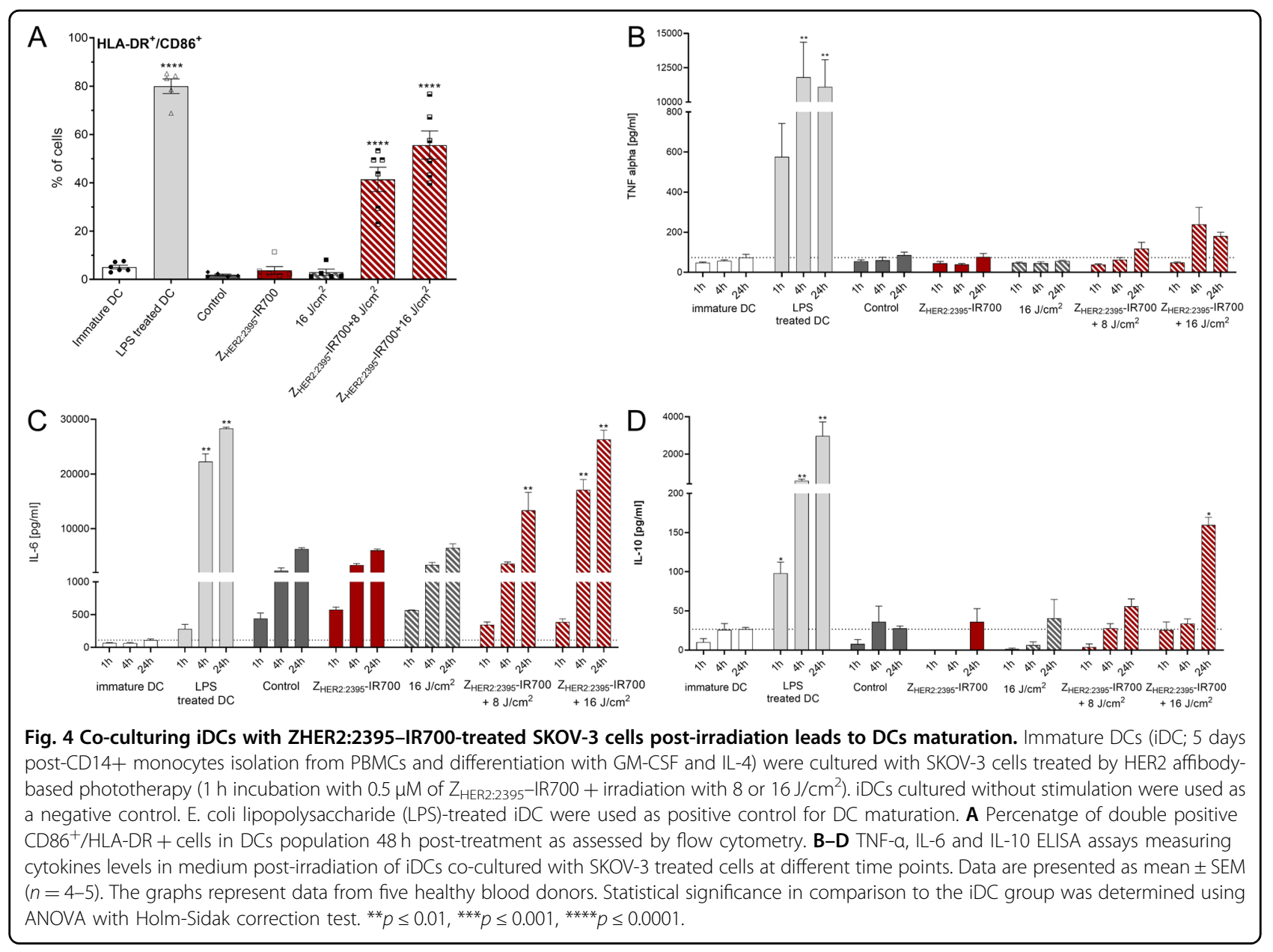

complete photobleaching of the fluorescence signal indicating that a sufficiently high light dose had been delivered (Fig. 6A). After the first treatment dose, tumour growth rate and body weight were measured every second day (Fig. 6B and Fig. S7A). Due to the slight increase in tumour volumes in the group treated with $\mathrm{Z}_{\mathrm{HER} 2: 2395^{-}}$ IR700 and light on days 14, 25 and 36, all the groups received a top-up treatment dose (Fig. 6B). Compared with either the control or $Z_{\text {HER2:2395-IR700 group alone, }}$

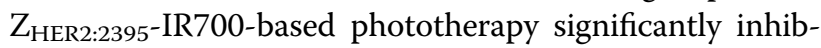
ited tumour growth $(\mathrm{p}<0.05$, control group vs.

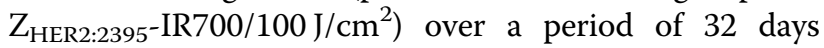
(Fig. 6B). Neither skin necrosis nor systemic toxicity was observed within any group. Of note, mice from the control groups had to be sacrificed earlier because their tumours exceeded size limits specified by institutional guidelines and the animal project licence. Importantly, mice treated with $\mathrm{Z}_{\mathrm{HER2} 2335}$-IR700-based phototherapy showed significantly higher median survival as compared to controls (Fig. S7B). Ex vivo analysis of tumour sections demonstrated distinct differences in tissue structure between control and treated mice, confirming that irradiation of $\mathrm{Z}_{\mathrm{HER} 2: 2395}$-IR700 led to extensive tumour necrosis (Fig. 6C). Ki-67 staining revealed a reduced cell proliferation index, especially on the margins of the treated tumours. Furthermore, in the control tumours we found only strong nuclear HMGB1 staining, whereas in the treated tumours HMGB1 was localised in the nuclei and cytoplasm (Fig. 6C).

\section{Discussion}

The development of tumour-targeted treatments that can drive immunogenic cancer cell death and influence the innate and adaptive anti-tumour immune response are of paramount importance. Several recent studies have demonstrated that PDT and mAb-based PIT can convert a 'cold', relatively immunosuppressive tumour microenvironment into a 'hot', inflammatory, immunogenic one, thereby increasing susceptibility to ICPIs $^{27,28}$. Therefore, we investigated whether phototherapy using IR700-based HER2-targeted affibody conjugate could (i) promote the release of DAMPs capable of inducing maturation of DCs in vitro and, (ii) delay tumour growth in receptor-positive xenografts. For that purpose, the 

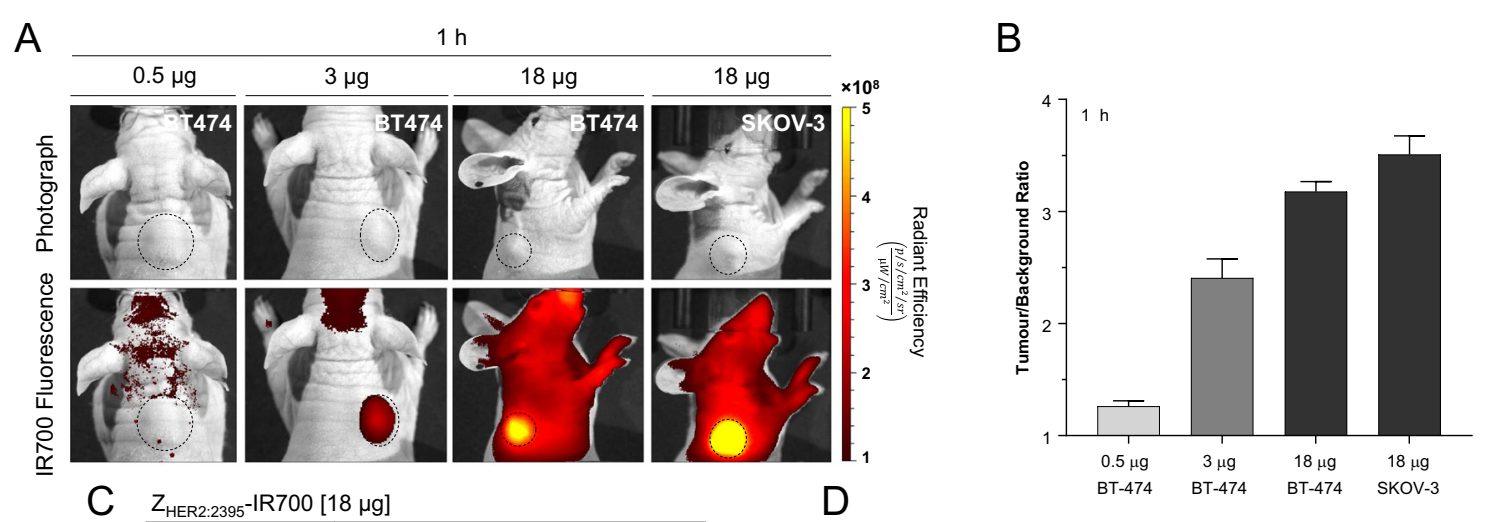

Z \begin{tabular}{|c|c|c|}
\hline HER2:2395 - IR700 $[18 \mu \mathrm{g}]$ \\
\cline { 2 - 3 } Organ & $\mathbf{B T}-\mathbf{4 7 4}$ Tumour/Organ Ratio \\
\hline Kidney & $0.15 \pm 0.03$ & $\mathbf{2 4} \mathbf{~}$ \\
\hline Liver & $1.12 \pm 0.11$ & $0.14 \pm 0.03$ \\
\hline Small intestine & $4.63 \pm 1.61$ & $3.60 \pm 0.77$ \\
\hline Lungs & $2.90 \pm 0.21$ & $6.25 \pm 1.31$ \\
\hline Muscle & $10.17 \pm 2.76$ & $12.55 \pm 3.35$ \\
\hline Heart & $9.10 \pm 0.47$ & $12.98 \pm 4.97$ \\
\hline
\end{tabular}

$\mathrm{E}$

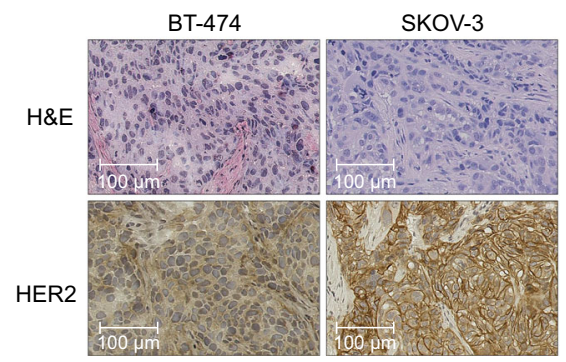

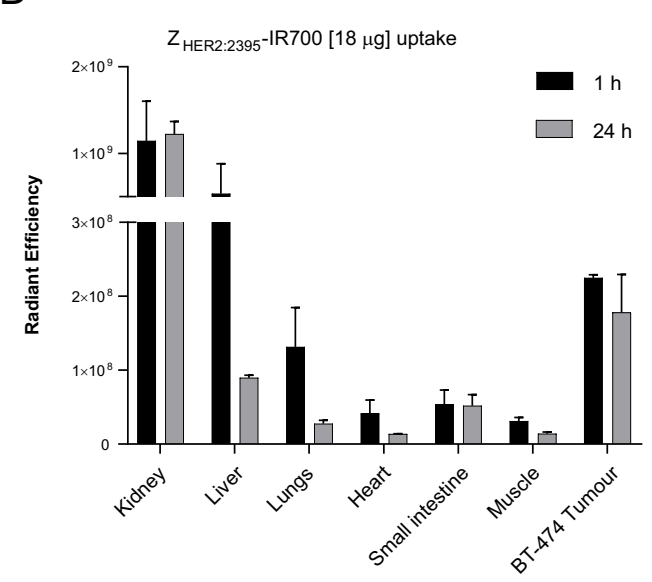

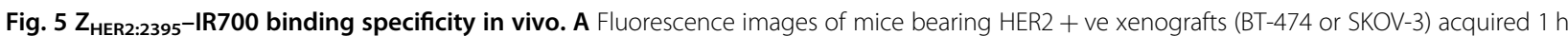

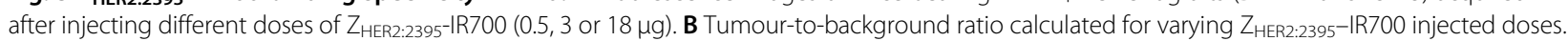
C, D Z HER2:2395-IR700 $(18 \mu \mathrm{g})$ uptake in excised tissues ( 1 and $24 \mathrm{~h}$ post-injection) and respective tumour-to-organ ratios. e HER2 and H\&E staining of HER2-positive tumour sections indicating higher HER2 expression in SKOV-3 then BT-474 xenograft. All data are presented as mean \pm SEM ( $n \geq 3$ ).

phthalocyanine dye IR700 was conjugated to affibody molecule $\mathrm{Z}_{\mathrm{HER} 2: 2395}$. The high binding affinity (nM range) to HER2, the small size and consequent great tumour penetration of $\mathrm{Z}_{\mathrm{HER} 2: 2395}$ make it an ideal targeting vector. Moreover, as $Z_{\text {HER2:2395 }}$ binds to a different HER2 epitope than therapeutic anti-HER2 mAbs, it would allow for their simultaneous application in future combinatorial treatment strategies. We initially confirmed the specificity of $Z_{\text {HER2:2395-IR700 binding to HER2-expressing cancer }}$ cells. Additionally, as high levels of ROS can elicit oxidative stress and cellular damage ${ }^{29}$, we demonstrated the conjugate's ability to produce ROS and singlet oxygen upon light irradiation. The treatment data showed a conjugate concentration- and light dose-dependent decrease in cell viability in response to $Z_{\text {HER2:2395-IR700 }}$ phototherapy, whereas only negligible cell death was observed when dye, $Z_{\text {HER2:2395-IR700, or light alone were }}$ applied. This clearly indicated that the target-specific binding of the conjugate combined with light treatment are required to induce cancer cell death. Consistent with other reports, we observed rapid necrotic cell death upon conjugate irradiation, as evidenced by bleb formation, cellular swelling and membrane rupture ${ }^{30,31}$. Interestingly, Sato et al. have recently reported that photochemical reactions following irradiation of $\mathrm{mAb}$-based IR700 conjugates may lead to a release of hydrophilic side chains of IR700 which changes the complex structure making the remaining molecule insoluble. This subsequently reduces cell membrane integrity due to the damage to transmembrane target proteins and allows the surrounding aqueous fluid to flow into the cell ${ }^{17}$. Whether, the exact same photochemical reaction might induce cell death post-NIR light irradiation of $Z_{\text {HER2:2395-IR700 }}$ will need to be investigated. However, the inhibition of cell death we observed when pre-treating the cells with ROS or apoptosis inhibitors seem to indicate multiple coexistent cell death mechanisms in response to $Z_{\text {HER2:2395- }}$ IR700 phototherapy. 


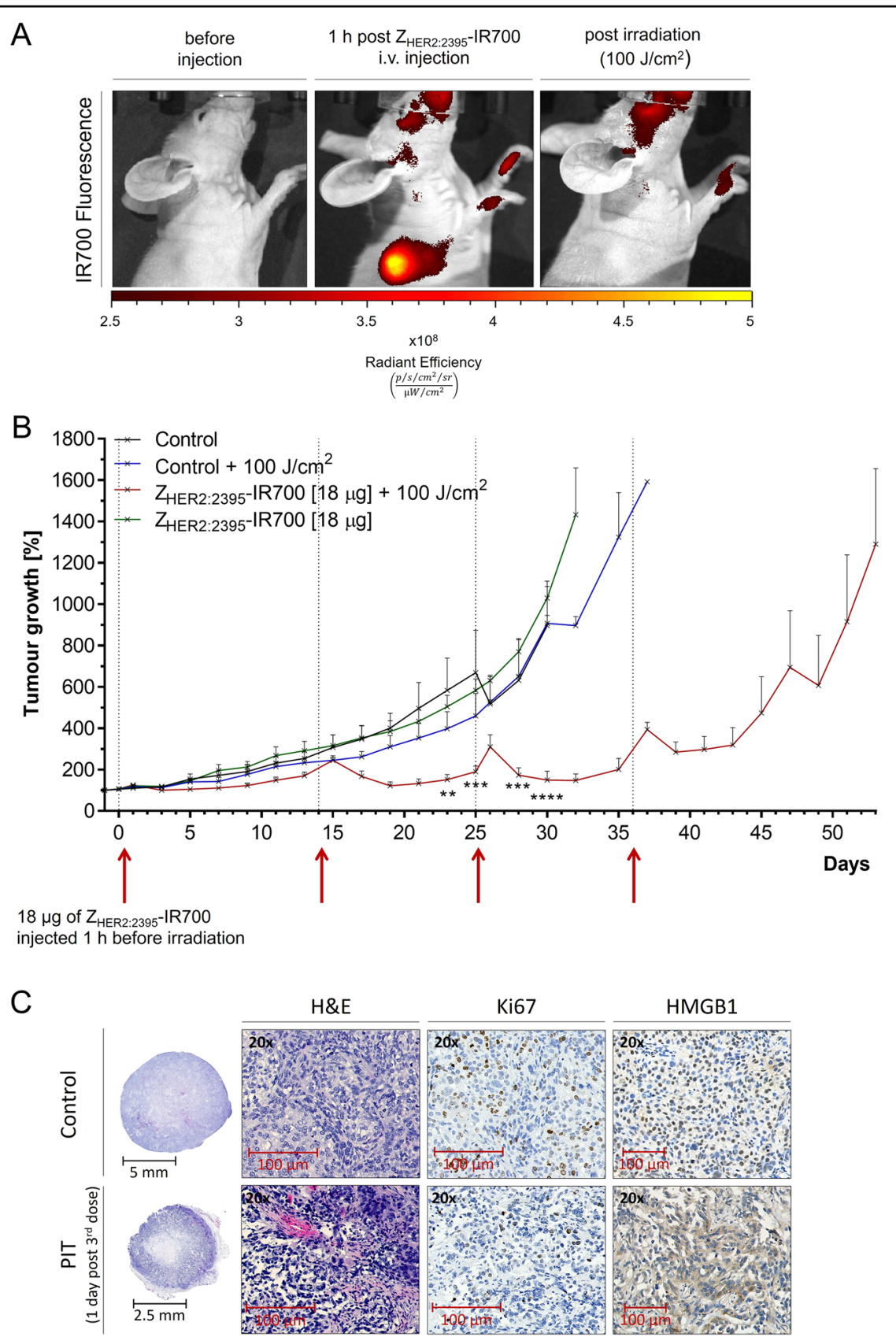

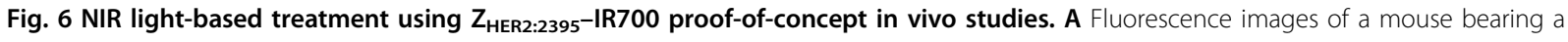
subcutaneous SKOV-3 tumour before, $1 \mathrm{~h}$ post-Z HER2:2395-IR700 $(18 \mu \mathrm{g})$ intravenous injection and immediately after irradiation with a light dose of $100 \mathrm{~J} / \mathrm{cm}^{2}$. B SKOV-3 tumour growth inhibition after four cycles of $Z_{\text {HER2:2395 }}-$ IR700 phototherapy $\left(18 \mu \mathrm{g} \mathrm{Z} Z_{\text {HER2:2395 }}-\right.$ IR700 $\left.+100 \mathrm{~J} / \mathrm{cm}^{2}\right)$ on day 0, 14,25 and 36 in comparison to the control groups. Data are presented as mean \pm SEM ( $n=3$ for each group). ${ }^{* *} p \leq 0.01,{ }^{* * *} p \leq 0.001,{ }^{* * *} p \leq 0.0001$ as assessed by unpaired multiple $t$ tests with Holm-Sidak correction. C H\&E, Ki67 and HMGB1 staining of SKOV-3 tumour sections collected after third cycle of the treatment. The images clearly show the presence of necrosis, decrease in cell proliferation and release of HMGB1 from the nuclei in the phototherapy-treated tumours.

Importantly, $\mathrm{Z}_{\mathrm{HER} 2: 2395}$-IR700 followed by exposure to a single dose of NIR light in vitro triggered the rapid activation of stress markers including translocation of CRT to the cell surface in SKOV-3 cells, as well as the secretion of ATP, HSP70/90 and HMGB1 into the medium. This was in line with previously published studies demonstrating that PDT and PIT induce $\mathrm{ICD}^{7,8,32}$. Given the fact that DAMPs exposed at the surface of dying cells result in DC activation and maturation as a prelude to priming antitumour adaptive $\mathrm{T}$ cell responses ${ }^{33}$, we differentiated 
peripheral blood mononuclear cells (PBMC) into immature DCs and subsequently co-cultured these cells with $\mathrm{Z}_{\text {HER2:2395-IR700 pre-treated cancer cells. Augmented }}$ expression levels of DC markers, including CD86 and MHC II (e.g. HLA-DR), were observed when DCs were co-cultured with SKOV-3 cells post-Z $Z_{\text {HER2:2395-IR700 }}$ phototherapy, indicating enhanced DC maturation. An increase in the level of inflammatory cytokines confirmed functional stimulation of DC. Importantly, no changes were detected in these markers when DCs were cocultured with untreated or irradiated SKOV-3 cells in the

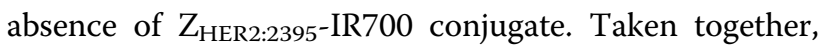
these in vitro results suggest that $Z_{\text {HER2:2395-IR700 pho- }}$ totherapy rapidly leads to ICD via cell death mechanisms (necrotic and/or apoptotic) that are associated with effective activation of DCs. In the case of necrosis, the cell membrane becomes damaged, resulting in the release of cellular contents into the extracellular space, and subsequent initiation of the inflammatory response that attracts antigen-presenting cells ${ }^{34}$. During apoptosis, on the other hand, these products are packaged into membrane-bound structures that can be consumed by DCs. Those, in turn, are capable of cross-presenting antigens to the immune system for the induction of $\mathrm{T}$ cell immunity $^{35,36}$. Therefore, the relationship between the mode of cancer cell death and the efficient induction of an anti-tumour immune response by phototherapy-based regimens is important.

Having successfully confirmed therapeutic effect of the conjugate in vitro, the response to $Z_{\text {HER2:2395-IR700 in vivo }}$ was investigated. A distinct fluorescent signal was observed in tumours as early as $1 \mathrm{~h}$ after i.v. injection of

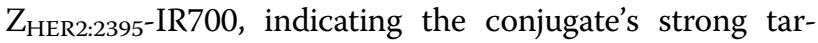
geting ability. Subsequently, we measured tumour uptake post-administration of three escalating doses of the conjugate, as studies reported by another group showed that increasing doses of mAb-IR700 correlated with greater treatment efficacy ${ }^{12}$. However, the use of high amounts of targeted agent may sometimes saturate receptors of interest, leading to non-specific binding in tissues surrounding the tumour. In this study, the relatively small molecular size of the affibody molecule and the rapid clearance of unbound conjugate ensured that high tumour-to-background contrast images were seen even at the highest investigated dose $(18 \mu \mathrm{g})$ just $1 \mathrm{~h}$ postinjection. In addition, biodistribution studies showed that the conjugate is still retained in the tumour at $24 \mathrm{~h}$ postinjection, which highlights the potential for its therapeutic applications. Apart from the tumour, increased uptake of the conjugate was found in the kidneys, which is associated with renal elimination and re-absorbance of the affibody ${ }^{26}$. Afterwards, we demonstrated that $Z_{\text {HER2:2395-IR700- }}$ mediated phototherapy, but not light or $\mathrm{Z}_{\mathrm{HER} 2: 2395}$-IR700 alone, led to a significant inhibition of SKOV-3 tumour growth and prolonged overall survival of mice from 30 to 52 days compared to vehicle control group. When Mitsunaga et al. performed a similar experiment using a oneoff mAb-IR700 PIT treatment in vivo, significant targetspecific tumour cell death was initially observed followed by tumour recurrence ${ }^{20}$. In order to enhance the effectiveness of $Z_{\text {HER2:2395-IR700, we based our treatment }}$ schedule on regular monitoring of tumour volume and delivering further phototherapy doses when the increase in volume was measured to be $\sim 15 \%$. We observed more necrotic regions in the group exposed to $Z_{\text {HER2:2395-IR700 }}$ and light than in the control group, as indicated by $\mathrm{H} \& \mathrm{E}$ staining. The additional dosing resulted also in a subsequent, yet short-term arrest in tumour growth. Interestingly, we found that after each therapy cycle the tumour volume temporarily increased. We speculate that the rapid cell death could lead to cytotoxic oedema, in which extracellular water passes into the cells resulting in their swelling.

In conclusion, we demonstrated that $\mathrm{Z}_{\mathrm{HER} 2: 2395}$-IR700 followed by exposure to NIR light led to HER2-specific cell death, consequent release of DAMPs and in vitro activation of DCs. Moreover, following treatment of HER2-positive xenografts, delayed tumour growth and increased median survival was observed.

Further studies using syngeneic mouse models will be needed to investigate the capability of affibody-IR700 mediated phototherapy to activate and expand tumourreactive cytotoxic $\mathrm{T}$ lymphocytes, which could provide clear indications of immunomodulatory activity of the conjugate and rationale for combinatorial approaches using affibody-based PIT with ICPIs. Furthermore, owing to the rapid and specific accumulation of $Z_{\text {HER2:2395-IR700 }}$ in HER2-positive tumours, the conjugate could be used in the clinic as a tool for both NIR fluorescence imageguided tumour resection and simultaneous light irradiation-mediated elimination of residual cancer cells as a trigger to activate the host anti-tumour immune responses. Such an approach could be an attractive alternative, particularly for patients whose tumours acquire resistance to conventional anti-HER2 therapies.

\section{Methods \\ Preparation of $Z_{\text {HER2:2395-IR700 }}$}

IRDye700DX-maleimide (IR700; ex. $689 \mathrm{~nm}, \quad$ em. $700 \mathrm{~nm}$; LI-COR Biosciences, US) was conjugated to the affibody molecule $Z_{\text {HER2:2395-Cys (supplied by Affi- }}$ bodyAB, Sweden) as previously described ${ }^{14}$. Some technical details are additionally given in the Supporting Information.

\section{Cell lines}

Breast (BT-474, MDA-MB-175, MDA-MB-231, and MDA-MB-468) and ovarian (SKOV-3) cancer cell lines 
were obtained from the American Type Tissue Culture Collection (ATCC, US). All cell lines were tested and authenticated by short tandem repeat (STR) DNA profiling analysis and confirmed to be mycoplasma-free. BT474, MDA-MB-468 cells were cultured in RPMI-1640 (Gibco, Life Technologies, US) and MDA-MB-175, MDAMB-231, SKOV-3 cells in DMEM (Gibco, Life Technologies, US), supplemented with $10 \%$ heat-inactivated fetal bovine serum (FBS, Gibco, Life Technologies, US) and maintained at $37^{\circ} \mathrm{C}$ in a humidified atmosphere supplied with $5 \% \mathrm{CO}_{2}$. The 3D-spheroids were grown in ultra-low attachment (ULA; Corning, Germany) 96-well round bottom plates as previously described ${ }^{37}$.

\section{Binding specificity in vitro}

To assess the expression level of HER2 and validate the binding specificity of $Z_{\text {HER2:2395-IR700 in vitro, flow }}$ cytometry was performed. A detailed description of the procedure is provided in the Supporting Information.

\section{Cellular accumulation of $\mathrm{Z}_{\text {HER2:2395-IR700 }}$}

To test the targeting specificity and internalisation of the conjugate, either MDA-MB-468 or SKOV-3 cells $\left(2 \times 10^{5}\right)$ were plated on confocal glass-bottomed dishes (MatTek, US) and incubated in a complete medium with $\mathrm{Z}_{\mathrm{HER} 2: 2395}$-IR700 $(1 \mu \mathrm{M})$ for $1 \mathrm{~h}$ at $4{ }^{\circ} \mathrm{C}$ or 1,4 and $6 \mathrm{~h}$ at $37^{\circ} \mathrm{C}$, respectively. To investigate the penetration of the conjugate, SKOV-3 3D spheroids were incubated either with $\mathrm{Z}_{\text {HER2:2395-IR700 }}(1 \mu \mathrm{M})$ or anti-HER2-FITC mAb $(1 \mu \mathrm{M}$, sc-23864, Santa Cruz Biotechnology, US) for $6 \mathrm{~h}$ in $37^{\circ} \mathrm{C}$. The detailed imaging and data analysis protocols are given in the Supporting Information.

\section{In vitro treatment studies}

The photocytotoxicity of either $Z_{\text {HER2:2395-IR700 }}$ $(0.01-1 \mu \mathrm{M})$ or free IR700 $(1 \mu \mathrm{M})$ was measured using CellTiter-Glo ${ }^{\circledR}$ luminescent assay (Promega, UK), on 2D and $3 \mathrm{D}$ cell cultures following $6 \mathrm{~h}$ incubation and irradiation $\left(16 \mathrm{~J} / \mathrm{cm}^{2}\right)$. Further experimental details are given in the Supporting Information.

\section{Annexin V/PI assay}

At 1 and $24 \mathrm{~h}$ post-irradiation, cells were resuspended in $0.1 \mathrm{~mL}$ of propidium iodide (PI; $0.5 \mu \mathrm{g} / \mathrm{mL}$ ) and Annexin V-AlexaFluor ${ }^{\text {TM }} 488$ (AnnexinV/Dead Cell Apoptosis Kit, Thermo Fisher Scientific, US) and subsequently analysed using $\mathrm{BD}^{\mathrm{TM}}$ LSRII flow cytometer. A detailed description of the procedure is given in the Supporting Information.

\section{Singlet oxygen and ROS detection}

To evaluate singlet oxygen $\left({ }^{1} \mathrm{O}_{2}\right)$ and ROS production in response to phototherapy, SKOV-3 cells were incubated with either the cell permeant reagent 2',7'-dichlorofluorescein diacetate (DCFDA; Cellular Reactive Oxygen
Species Detection Assay Kit; Abcam, UK) or SOSGR (Singlet Oxygen Sensor Green Reagent; Molecular Probes, US) reagents with or without $\mathrm{Z}_{\mathrm{HER} 2: 2395}$-IR700 $(1 \mu \mathrm{M})$, IR700 $(1 \mu \mathrm{M})$ or medium alone for $6 \mathrm{~h}$ at $37^{\circ} \mathrm{C}$. Post-light irradiation the fluorescence was measured according to the manufacturer's protocol using a FLUOstar Omega microplate reader (ex. filter: $485 \mathrm{~nm}$, em. filter: $520 \mathrm{~nm}$; BMG Labtech, Germany).

\section{Western blot}

Cell lysates were prepared as previously described ${ }^{38}$. A complete list of used antibodies and the detailed methods are provided in the Supporting Information.

\section{Measurement of ATP secretion}

In order to determine ATP secretion post-phototherapy, the ENLITEN ${ }^{\circledR}$ test (Promega, US) was used. SKOV-3 cells were seeded in cell-culture dishes and treated as described in the above section "Annexin V/PI assay". The medium from each dish was collected at $5 \mathrm{~min}, 30 \mathrm{~min}, 1 \mathrm{~h}$ and $24 \mathrm{~h}$ post-light irradiation and centrifuged at $500 \times g$ for $5 \mathrm{~min}$ at $4{ }^{\circ} \mathrm{C}$. The supernatants were used to determine the extracellular ATP concentration according to the manufacturer's instruction.

\section{Measurement of HMGB1 release}

To quantify HMGB1 released from SKOV-3 cells post$Z_{\text {HER2:2395-IR700 irradiation, culture supernatants from }}$ indicated cells were collected and centrifuged at low speed $\left(500 \times \mathrm{g}\right.$ for $5 \mathrm{~min}$ at $\left.4{ }^{\circ} \mathrm{C}\right)$ to clear cell debris. HMGB1 concentration was measured using an ELISA kit (Tecan, IBL International, Germany) per manufacturer's guidelines.

\section{Monitoring calreticulin translocation}

To visualise calreticulin membrane translocation via confocal microscopy, methanol-fixed control or treated $\left(0.1 \mu \mathrm{M} \mathrm{Z} \mathrm{Z}_{\mathrm{HER} 2: 2395}\right.$-IR700 $\left.+8 \mathrm{~J} / \mathrm{cm}^{2}\right)$ SKOV-3 cells were blocked with $5 \%$ bovine serum albumin and incubated overnight with anti-calreticulin $\mathrm{mAb}$ conjugated to Alexa Fluor ${ }^{\circledR} 405$ (ab210431, Abcam, UK). To measure calreticulin membrane exposition post-phototherapy $(0.1 \mu \mathrm{M}$ $Z_{\left.\text {HER2:2395-IR700 }+8 \mathrm{~J} / \mathrm{cm}^{2}\right)}$ cells were collected and incubated with anti-calreticulin mAb (1:100; PA3-900, Thermo Fisher Scientific, US) for $30 \mathrm{~min}$ at $4{ }^{\circ} \mathrm{C}$, followed by $30 \mathrm{~min}$ incubation with secondary Alexa-Fluor488labeled mAb (1:1000, A-11008, Thermo Fisher Scientific, US). Only viable cells (PI negative) were taken for flow cytometry analysis.

\section{Dendritic cells co-culture}

Perpheral blood mononuclear cells (PBMCs) were isolated from leukocyte cones (NC24) obtained from healthy donors supplied by the NHS blood and transplant service 
(UK) by Ficoll (GE Healthcare, US) gradient centrifugation (according to MACS Miltenyi Biotec protocol). CD14 + monocytes were seperated from PBMCs via magnetic positive selection using CD14+ beads and MACS column (Miltenyi Biotec, Germany). Immature dendritic cells (iDC) were culture in RPMI medium supplemented with FBS, interleukin-4 (IL-4, $500 \mathrm{U} / \mathrm{ml}$; PeproTech, US) and granulocyte-macrophage colony-stimulating factor (GMCSF, $800 \mathrm{U} / \mathrm{ml}$; PeproTech) for 5 days. Next, the coculture of iDC and $\mathrm{Z}_{\mathrm{HER} 22395}$-IR700-treated SKOV-3 cells (ratio 1:2 iDC/cancer cell) was irradiated $\left(16 \mathrm{~J} / \mathrm{cm}^{2}\right)$. DC maturation was induced by stimulating the iDC with $\mathrm{E}$. coli lipopolysaccharide (LPS, $100 \mathrm{ng} / \mathrm{ml}$; Sigma) for $12 \mathrm{~h}$ (a positive control). After $48 \mathrm{~h}$, all floating cells were collected and with Pacific Blue ${ }^{\mathrm{TM}}$ anti-human CD14 (\#367121), FITC anti-human CD86 (\#374204) and APC anti-human HLA-DR (\#307610) (all antibodies from BioLegend, US) and PI. DC maturation was evaluated on single, live (PI-) and CD14- gated cells populations by flow cytometry. Cell supernatants were collected at different time points and used for anti-IL6, anti-IL-10 and anti-TNF- $\alpha$ ELISA assays according to manufacture protocols (BioLegend, US).

\section{Animals}

All animal experiments were conducted in compliance with licences issued under the UK Animals (Scientific Procedures) Act 1986 and following local ethical review. Studies were compliant with the United Kingdom National Cancer Research Institute Guidelines for Animal Welfare in Cancer Research ${ }^{39}$. Female NSG nude mice (6-8 weeks old) obtained from the in-house breeding colony were used in the animal studies.

\section{In vivo biodistribution and therapy}

To evaluate $Z_{\text {HER2:2395-IR700 accumulation and efficacy }}$ post-irradiation in vivo, mice bearing subcutaneous SKOV-3 or BT-474 tumours implanted on the right shoulder $\left(7 \times 10^{6}\right.$ cells $/ 0.1 \mathrm{~mL}$ PBS/Matrigel; $20 \% \mathrm{v} / \mathrm{v} \%$; BD Matrigel ${ }^{\mathrm{TM}}$ Matrix, BD Bioscience, US) were used. When the tumours reached $\sim 50-100 \mathrm{~mm}^{3}$, mice were

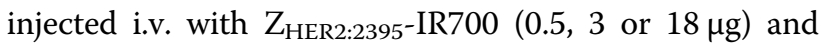
imaged at the indicated time points using the IVIS/ Spectrum imaging system (ex. filter: $675 \mathrm{~nm}$, em. filter: $720 \mathrm{~nm}$; PerkinElmer, US). Regions of interest (ROIs) were drawn around the tumours and background tissue, and the average radiant efficiency $\left(\left(\mathrm{p} / \mathrm{s} / \mathrm{cm}^{2} / \mathrm{sr}\right) \times \mathrm{cm}^{2} /\right.$ $\mu \mathrm{W})$ in each ROI was calculated. To determine the conjugate distribution, mice were sacrificed by cervical dislocation at 1 and $24 \mathrm{~h}$ post-injection of $\mathrm{Z}_{\text {HER2:2395-IR700 }}$ and major tissues and tumours were collected for ex vivo fluorescence imaging. The tumour-to-organ ratios were determined and used to select the optimal conditions for the following treatment studies. For proof of concept therapy studies, mice ( $n=5$ per group) were randomly assigned to the following groups: (i) no treatment, (ii) light

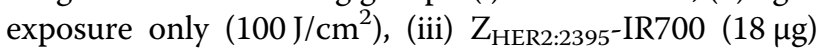

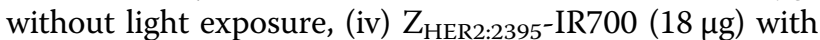
light exposure $\left(100 \mathrm{~J} / \mathrm{cm}^{2}\right)$. The detailed treatment and biodistribution protocol is given in the Supporting Information.

\section{Immunohistochemical analysis}

Spheroids submerged in agar and paraformaldehydefixed tumours were embedded in paraffin, sectioned into 4-5 $\mu \mathrm{m}$-thick slices, and mounted on microscope slides. The detailed staining procedures with the various antibodies are described in the Supporting Information.

\section{Statistical analysis}

Unless otherwise stated, data were expressed as the mean \pm SEM. Statistical significance, sample size calculations and correlation analysis are described in detail in the Supporting Information.

\section{Acknowledgements}

We gratefully thank AffibodyAB (Stockholm, Sweden) for supplying the

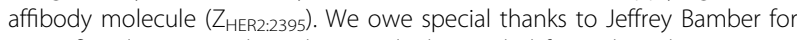
scientific advice, Daniela Ciobota and Olga Michel for technical support, Richard Symonds-Tayler for building the electronics box which provides the digital power control for the LED and Meirion Richards for mass spectrometry (The Institute of Cancer Research (ICR), London, UK). This work was funded by the National Science Centre, Poland (Project No. 2015/19/N/NZ7/01336) and supported by funding from the ICR and NIHR Clinical Research Facility at the Royal Marsden, London, UK. The first author (J. Mączyńska) obtained a doctoral scholarship funded by the National Science Centre, Poland (Project No. 2016/ 20/T/NZ7/00522). K.J. Harrington acknowledges support from the RM/ICR National Institute for Health Research Biomedical Research Centre.

\section{Author details}

'Division of Radiotherapy and Imaging, The Institute of Cancer Research, London, UK. ${ }^{2}$ Department of Medical Biochemistry, Wroclaw Medical University, Wroclaw, Poland. ${ }^{3}$ Department of Molecular and Cellular Biology, Wroclaw Medical University, Wroclaw, Poland

\section{Conflict of interest}

The authors declare that they have no conflict of interest.

\section{Publisher's note}

Springer Nature remains neutral with regard to jurisdictional claims in published maps and institutional affiliations.

Supplementary Information accompanies this paper at (https://doi.org/ 10.1038/s41419-020-03077-6).

Received: 12 November 2019 Revised: 29 September 2020 Accepted: 1 October 2020

Published online: 20 October 2020

\footnotetext{
References

1. Sharpe, A. H. Introduction to checkpoint inhibitors and cancer immunotherapy. Immunol. Rev. 276, 5-8 (2017).

2. Zhang, L. et al. Unique photochemo-immuno-nanoplatform against orthotopic xenograft oral cancer and metastatic syngeneic breast cancer. Nano Lett. 18, 7092-7103 (2018).
} 
3. Sharma, P., Hu-Lieskovan, S., Wargo, J. A. \& Ribas, A. Primary, adaptive, and acquired resistance to cancer immunotherapy. Cell 168, 707-723 (2017).

4. Binnewies, $M$. et al. Understanding the tumor immune microenvironment (TIME) for effective therapy. Nat. Med. 24, 541-550 (2018).

5. Nagarsheth, N., Wicha, M. S. \& Zou, W. P. Chemokines in the cancer microenvironment and their relevance in cancer immunotherapy. Nat. Rev. Immunol. 17, 559-572 (2017).

6. Garg, A. D. et al. A novel pathway combining calreticulin exposure and ATP secretion in immunogenic cancer cell death. EMBO J. 31, 1062-1079 (2012).

7. Ogawa, M. et al. Immunogenic cancer cell death selectively induced by near infrared photoimmunotherapy initiates host tumor immunity. Oncotarget $\mathbf{8}$, 10425-10436 (2017)

8. Tanaka, M. et al. Immunogenic cell death due to a new photodynamic therapy (PDT) with glycoconjugated chlorin (G-chlorin). Oncotarget 7, 47242-47251 (2016).

9. Hirschberg, H., Berg, K. \& Peng, Q. Photodynamic therapy mediated immune therapy of brain tumors. Neuroimmun. Neuroinflamm. https://doi.org/ 10.20517/2347-8659.2018.31 (2018).

10. Galluzzi, L., Buque, A., Kepp, O., Zitvogel, L. \& Kroemer, G. Immunogenic cell death in cancer and infectious disease. Nat. Rev. Immunol. 17, 97-111 (2017).

11. Kobayashi, H. \& Choyke, P. L. Near-infrared photoimmunotherapy of cancer. Acc. Chem. Res. 52, 2332-2339 (2019).

12. Mitsunaga, M. et al. Cancer cell-selective in vivo near infrared photoimmunotherapy targeting specific membrane molecules. Nat. Med. 17 1685-1691 (2011).

13. Zhen, Z. et al. Protein nanocage mediated fibroblast-activation protein targeted photoimmunotherapy to enhance cytotoxic $T$ cell infiltration and tumor control. Nano Lett. 17, 862-869 (2017).

14. Burley, T. A. et al. Near-infrared photoimmunotherapy targeting EGFR-Shedding new light on glioblastoma treatment. Int. J. cancer 142, 2363-2374 (2018).

15. Okada, R. et al. The effect of antibody fragments on CD25 targeted regulatory $T$ cell near-infrared photoimmunotherapy. Bioconjug. Chem. 30, 2624-2633 (2019).

16. Hussain, A. F. et al. SNAP-tag technology mediates site specific conjugation of antibody fragments with a photosensitizer and improves target specific phototoxicity in tumor cells. Bioconjug. Chem. 22, 2487-2495 (2011).

17. Sato, K. et al. Photoinduced ligand release from a silicon phthalocyanine dye conjugated with monoclonal antibodies: a mechanism of cancer cell cytotoxicity after near-infrared photoimmunotherapy. ACS Cent. Sci. 4, 1559-1569 (2018).

18. Anderson, E. D., Gorka, A. P. \& Schnermann, M. J. Near-infrared uncaging or photosensitizing dictated by oxygen tension. Nat. Commun. 7, 13378 (2016)

19. Sato, K et al. Spatially selective depletion of tumor-associated regulatory $T$ cells with near-infrared photoimmunotherapy. Sci. Transl. Med. https:/doi.org/ 10.1126/scitranslmed.aaf6843 (2016).

20. Mitsunaga, M. et al. Immediate in vivo target-specific cancer cell death after near infrared photoimmunotherapy. BMC Cancer 12, 345 (2012).

21. Yan, M., Parker, B. A., Schwab, R. \& Kurzrock, R. HER2 aberrations in cancer: Implications for therapy. Cancer Treat. Rev. 40, 770-780 (2014).
22. Arteaga, C. L. et al. Treatment of HER2-positive breast cancer: current status and future perspectives. Nat. Rev. Clin. Oncol. 9, 16-32 (2012).

23. Burstein, H. J. The distinctive nature of HER2-positive breast cancers. N. Engl. J. Med. 353, 1652-1654 (2005).

24. Verma, S. et al. Trastuzumab emtansine for HER2-positive advanced breast cancer. N. Engl. J. Med. 367, 1783-1791 (2012)

25. Bates, J. P., Derakhshandeh, R., Jones, L. \& Webb, T. J. Mechanisms of immune evasion in breast cancer. BMC Cancer. https://doi.org/10.1186/S12885-0184441-3 (2018).

26. Altai, M. et al. In vivo and in vitro studies on renal uptake of radiolabeled affibody molecules for imaging of HER2 expression in tumors. Cancer Biother. Radiopharm. 28, 187-195 (2013).

27. Muchowicz, A. et al. Inhibition of lymphangiogenesis impairs antitumour effects of photodynamic therapy and checkpoint inhibitors in mice. Eur. J. Cancer 83, 19-27 (2017)

28. He, C. et al. Core-shell nanoscale coordination polymers combine chemotherapy and photodynamic therapy to potentiate checkpoint blockade cancer immunotherapy. Nat. Commun. 7, 12499 (2016).

29. Panieri, E. \& Santoro, M. M. ROS homeostasis and metabolism: a dangerous liason in cancer cells. Cell Death Dis. 7, e2253 (2016).

30. Ito, K. et al. Molecular targeted photoimmunotherapy for HER2-positive human gastric cancer in combination with chemotherapy results in improved treatment outcomes through different cytotoxic mechanisms. BMC cancer 16, 37 (2016).

31. Ogata, F. et al. Dynamic changes in the cell membrane on three dimensional low coherent quantitative phase microscopy (3D LC-QPM) after treatment with the near infrared photoimmunotherapy. Oncotarget 8, 104295-104302 (2017).

32. Korbelik, M., Zhang, W. \& Merchant, S. Involvement of damage-associated molecular patterns in tumor response to photodynamic therapy: surface expression of calreticulin and high-mobility group box-1 release. Cancer Immunol. Immunother. 60, 1431-1437 (2011).

33. Krysko, D. V. et al. Immunogenic cell death and DAMPs in cancer therapy. Nat Rev. Cancer 12, 860-875 (2012)

34. Castano, A. P., Mroz, P. \& Hamblin, M. R. Photodynamic therapy and antitumour immunity. Nat. Rev. Cancer 6, 535-545 (2006).

35. Proskuryakov, S. Y., Konoplyannikov, A. G. \& Gabai, V. L. Necrosis: a specific form of programmed cell death? Exp. Cell Res. 283, 1-16 (2003).

36. Blachere, N. E., Darnell, R. B. \& Albert, M. L. Apoptotic cells deliver processed antigen to dendritic cells for cross-presentation. PLoS Biol. 3, e185 (2005).

37. Vinci, M. et al. Advances in establishment and analysis of three-dimensional tumor spheroid-based functional assays for target validation and drug evaluation. BMC Biol. 10, 29 (2012).

38. Kramer-Marek, G., Kiesewetter, D. O. \& Capala, J. Changes in HER2 expression in breast cancer xenografts after therapy can be quantified using PET and (18)Flabeled affibody molecules. J. Nucl. Med. 50, 1131-1139 (2009).

39. Workman, P. et al. Guidelines for the welfare and use of animals in cancer research. Brit J. Cancer 102, 1555-1577 (2010). 